\title{
Conditioned media from human adipose-derived stem cell culture in some stressed culture conditions differ angiogenic potential
}

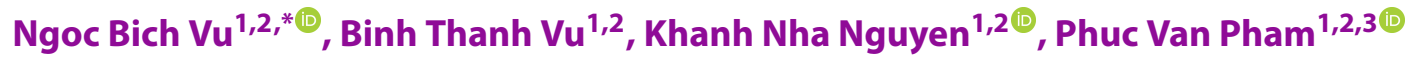

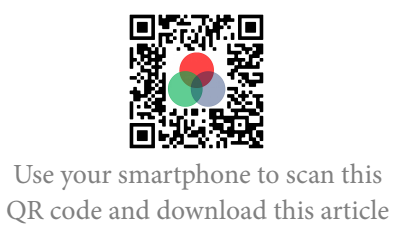

${ }^{1}$ Stem Cell Institute, University of Science Ho Chi Minh City, Viet Nam

${ }^{2}$ Viet Nam National University Ho Chi Minh City, Viet Nam

${ }^{3}$ Laboratory of Stem Cell Research and Application, University of Science Ho Chi Minh City, Viet Nam

Correspondence

Ngoc Bich Vu, Stem Cell Institute, University of Science Ho Chi Minh City, Viet Nam

Viet Nam National University Ho Chi Minh City, Viet Nam

Email: ngocvu@sci.edu.vn

\section{History}

- Received: Mar 20, 2021

- Accepted: Jun 20, 2021

- Published: Jun 30, 2021

DOI : 10.15419/bmrat.v8i6.680

\section{Check for updates}

\section{Copyright}

(c) Biomedpress. This is an openaccess article distributed under the terms of the Creative Commons Attribution 4.0 International license.

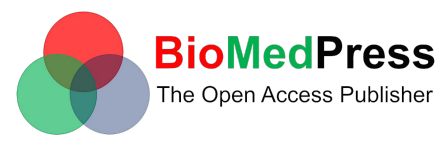

\begin{abstract}
Introduction: The potency of mesenchymal stem cells (MSCs) related to their biological effects includes immune modulation and angiogenesis. Recently, some stress conditions were applied to enhance the angiogenic potential of MSCs. This study aimed to assess the effects of conditioned media (CM) collected from adipose-derived stem cells' (ADSCs') culture under various stress conditions on angiogenesis in vitro. Methods: ADSCs were isolated and expanded according to a published protocol. These cells were treated with some stress conditions including hypoxia, starvation, a combination of hypoxia and starvation, and tissue necrosis factor-alpha (TNF-alpha) treatment. CM from these cultures were collected and used for further experiments. The angiogenic potential of CM was evaluated through stimulation of human umbilical vein endothelial cells (HUVECs) to form vessels in vitro. ELISA was used to measure the VEGF concentrations in CM. Results: CMderived various stress ADSC cultures differently affected angiogenesis of HUVECs. The supernatant from a hypoxic culture of ADSCs contained the highest concentration of VEGF and was higher than normoxic culture. However, in others, VEGF concentrations in CM significantly reduced compared to control. CM from TNF-alpha treatment failed to support the formation of blood vessels from HUVECs, while other conditions could support blood vessel formation in vitro. TNF-alpha dually affected both ADSCs and HUVECs. Furthermore, TNF-alpha could stimulate or suppress the VEGF production in dose-response in ADSCs and cause apoptosis in HUVECs at high concentrations. Conclusion: CM from the hypoxic culture of ADSCs contained a high concentration of VEGF, supporting angiogenesis of HUVECs well. This is a simple technique that can be used in translational applications. However, the use of TNF-alpha yielded dual effects on ADSCs and HUVECs. Although the VEGF production was enhanced at a low dose of TNF-alpha, they could induce apoptosis in endothelial cells to cause the failure of angiogenesis.

Key words: Adipose derived stem cells, Angiogenic potential, Conditioned medium, Mesenchymal stem cells, Stressed stem cells
\end{abstract}

\section{INTRODUCTION}

Mesenchymal stem cells (MSCs) are the most commonly used stem cells in clinical applications. The potency of MSCs is generally based on their immune modulation and angiogenesis that can promote tissue regeneration and inhibit scarring ${ }^{1-3}$. Some recent studies have shown that the biological effects of MSCs depend on their secretomes ${ }^{4-7}$. Moreover, MSC-derived secretomes can cause bioeffects compared to whole living cells ${ }^{8,9}$.

Ho et al. (2017) showed that both MSCs and their conditioned media (CM) could enhance uterine defect repair in vivo through paracrine involvement IL$6^{8}$. CM-MSCs could also reduce cartilage damage and modulate the immune responses in inflammatory arthritis in mice ${ }^{5}$, ameliorate Parkinson's symptoms in rat models $^{9}$, protect cholinergic neurons in the medial septum ${ }^{10}$, and prevent the ovarian injury through cisplatin in animal models ${ }^{11}$. In animal models, Hong et al. (2020) showed that CM-MSCs could decrease the apoptosis of oocytes and granulosa cells affected by cisplatin ${ }^{11}$.

Some studies have demonstrated the role of CMMSCs in angiogenesis ${ }^{12,13}$. Shen et al. (2015) demonstrated that CM from umbilical-cord-derived MSCs could enhance angiogenesis through SDF-1, MCP1, HGF, VCAM-1, IL-8, IGF-1, and VEGF ${ }^{12}$. Lu et al. (2018) proved that CM from adipose-derived stem cells (ADSCs) were more efficient in angiogenesis than MSCs from the umbilical cord and endothelium tissues ${ }^{13}$ in both in vitro and in vivo conditions. This characteristic depends on the higher levels of many cytokines, and MMPs produced in ADSCs than others, including VEGF, bFGF, PDGF-BB, IGNgamma, IL-10, chemerin, MMP-9, and MMP-13 ${ }^{13}$.

To improve the angiogenic effects of CM from MSC culture, there have been some recent efforts to treat MSCs in some stress conditions or gene modification $^{14-19}$. Ogisu et al. (2020) cultured MSCs from 
the bone marrow in cyclic stretch stimulation conditions for $24 \mathrm{~h}$, and showed that their $\mathrm{CM}$ contained more VEGF, BMP-2, and BMP-4 than the control ${ }^{14}$. In an in vivo assay, the $\mathrm{CM}$ from the stress condition showed greater angiogenic effects than control ${ }^{14}$. Chen et al. (2014) demonstrated that CM from the hypoxia culture of MSCs enhanced wound healing ${ }^{20}$. CM from hypoxia culture of ADSCs also promoted the healing of the gastric mucosal injury in a rodent model ${ }^{21}$. In another study, Almeria et al. (2019) demonstrated that extracellular vesicles (EVs) from the hypoxic culture of MSCs significantly increased vascular tube formation in vitro in HUVECs compared to normoxia ${ }^{15}$. Furthermore, Zhu et al. (2018) reported that exosomes derived from hypoxia $\mathrm{CM}$ of MSCs facilitated ischemic cardiac repair by ameliorating cardiomyocyte apoptosis ${ }^{16}$.

Starvation is another stress condition used to promote stemness and angiogenesis in MSCs as reported in a few articles ${ }^{17,22-24}$. In a reduced serum condition ( $2 \%$ serum compared to the usual $10 \%$ serum), ADSCs reduced their proliferation but enhanced VEGF production $^{23}$. However, a later study showed that MSCs cultured in a serum-reduced medium decreased the expression of VEGF, MCP-1, MIP-1 alpha, MIP-1 beta, MMP-2 compared to the normal level of serum ${ }^{22}$. Conversely, MSCs improved their exosome's activities in a condition of serum deprivation $^{24}$. In a recent study, Shin et al. (2019) showed that in the case of Wharton's jelly-derived MSCs, they produced less protein in the serum-free medium than in the serum medium ${ }^{17}$.

Jin et al. (2020) expressed FGF-2 in gingival MSCs (GMSCs) to produce MSCs with high expression of FGF-2 (FGF ${ }^{+} \mathrm{GMSCs}^{18}$. $\mathrm{FGF}^{+}$GMSCs could produce more FGF-2, VEGF, and TGF-beta than the original GMSCs. The CM collected from the culture of $\mathrm{FGF}^{+}$GMSCs could trigger the expression of PLGF, SCF, and VEGFR2 in HUVECs ${ }^{18}$. Similar to this strategy, Park et al. (2020) engineered MSCs to express HGF ( $\mathrm{HGF}^{+} \mathrm{MSCs}$ ) and used them to repair cardiac injury in animal models. $\mathrm{HGF}^{+} \mathrm{MSC}$ could survive longer than the original cells (MSCs) in the 3D cardiac patch and conferred cardioprotection ${ }^{19}$.

In this study, we aimed to compare the angiogenic potential of CM derived from ADSC cultures in certain stress culture conditions including hypoxia ( $2 \%$ oxygen), starvation ( $0 \%$ serum), a combination of hypoxia and starvation, and a TNF-alpha treatment. Furthermore, we aimed to determine the suitable stress that can be used to produce CM from ADSCs with the strongest angiogenic potential from the results.

\section{METHODS}

\section{ADSC isolation and characterization}

ADSCs were isolated and expanded as per the previous published works ${ }^{25-27}$. Adipose tissues were collected at the hospital with consent forms. These tissues were discarded during the aesthetic surgery. The use of these samples for the study was approved by the institutional ethical committee. At the laboratory, the tissues were washed twice with a washing buffer (PBS), and then the stromal vascular fraction (SVF) was extracted from the adipose tissue using the Cell Extraction Kit (Regenmedlab, HCMC, VN). The SVF pellet was re-suspended in the ADSCCult I primary (Regenmedlab, HCMC, VN) at the ratio of $10^{6}$ SVF cells per $\mathrm{mL}$. The cell suspension was plated in the T75 flask for five days without any replacement of the medium. After five days of incubation at 37 ${ }^{\circ} \mathrm{C}$ with $5 \% \mathrm{CO}_{2}$, the flasks were refreshed with 10 $\mathrm{mL}$ of fresh media. When the primary cells reached $70-80 \%$ confluency, they were sub-cultured in new flasks at a splitting ratio of 1:3 using the ADSCCult I medium (Regenmedlab, HCMC, VN). The ADSCs in the $5^{t h}$ passages were characterized as MSC phenotypes as suggested by ISCT for minimal MSC crite$\mathrm{ria}^{28}$.

ADSCs checked the surface marker expression by flow cytometry. The expression of CD14, CD34, CD44, CD45, CD73, CD90, CD105, and HLA-DR was evaluated using the respective antibodies. Briefly, for each marker, the $5.10^{5}$ cells were resuspended in $100 \mathrm{~mL}$ of staining buffer (BD Bioscience, MA), and then 5 $\mathrm{uL}$ of monoclonal antibody conjugated with dye were added into the tube an incubated at RT for $30 \mathrm{~min}$ in the dark. Thereafter, the tubes were centrifuged to remove the extra-monoclonal antibody and washed twice using the washing buffer. The Stained cells were analyzed by FACSCalibur flow cytometry and FlowJo software (both from BD Bioscience, MA).

The differentiation potential of ADSCs was checked as per the previous published works [25-27]. ADSCs were cultured and induced in commercial differentiation media including adipogenesis, osteogenesis, and chondrogenesis to enable their differentiation into adipocytes, osteoblasts, and chondroblasts, respectively (Thermo Fisher, MA). On the $21^{\text {st }}$ day after differentiation, the induced cells were stained with Oil Red O, Alizarin Red, and Safranin O to confirm the phenotypes of adipocytes, osteoblasts, and chondrocytes, respectively. 


\section{Conditioned media (CM) preparation}

One million ADSCs were seeded in the T75 flask and incubated at $37{ }^{\circ} \mathrm{C}$ with $5 \% \mathrm{CO}_{2}$ until reaching $70 \%$ confluency. The flasks were refreshed with fresh culture media. For group control (G0), hypoxia (group 3-G3) culture media (ADSCCult I completed medium, Regenemedlab) were used. For group 1 (G1), the completed culture medium with $100 \mathrm{ng} / \mathrm{mL}$ of TNF-alpha was used. For group $2(\mathrm{G} 2)$ and group 4 (G4), the basal medium of ADSCCult I (DMEM/F12) was used. The flasks of G3 and G4 were placed in the $5 \%$ oxygen incubators (Binder, Germany). The flasks of other groups were incubated in $20 \%$ oxygen, with $5 \% \mathrm{CO}_{2}$, and at $37^{\circ} \mathrm{C}$. All flasks were incubated for $48 \mathrm{~h}$; then, the supernatants were collected in $50 \mathrm{~mL}$ centrifuge tubes. The supernatants were centrifuged at 3,000 $\mathrm{g}$ at $4{ }^{\circ} \mathrm{C}$ for $15 \mathrm{~min}$ to remove debris. Finally, the $\mathrm{CM}$ were kept in a $-86-^{\circ} \mathrm{C}$ freezer for further experiments.

\section{Blood vessel formation assay}

This assay was performed using the Angiogenesis Starter Kit (Thermo Fisher, MA). First, the HUVECs included in the kit were expanded using the M200 medium supplemented with LVES (included in the kit). Subsequently, the Geltrex matrix was prepared as instructed and used to cover the surface of wells of 96well plates. Thereafter, HUVECs were collected and re-suspended in CM (G0: control, G1: TNF-alpha, G2: starvation, G3: hypoxia 5\% oxygen, and G4: hypoxia $5 \%$ oxygen and starvation) and positive control using M200 medium supplemented with LVES. Next, HUVECs were cultured in CM and M200 medium supplemented with LVES for $48 \mathrm{~h}$ at $37{ }^{\circ} \mathrm{C}$, with $5 \%$ $\mathrm{CO}_{2}$, and in $20 \%$ oxygen. Finally, blood vessel formation was observed under an inverted microscope (Carl Zeiss, Germany).

\section{VEGF concentration measurement}

$\mathrm{CM}$ were collected and kept at $-86{ }^{\circ} \mathrm{C}$ after removing the cell debris prior to use in this assay. The VEGF concentrations were measured using the VEGF ELISA kits (Abcam). All protocols were performed following the manufacturer's guidelines.

\section{Effects of TNF-alpha on VEGF secretion of ADSCs and apoptosis of HUVECs}

A serial concentration of TNF-alpha $(0,10,20,40,60$, 80 , and $100 \mathrm{ng} / \mathrm{mL}$ of TNF-alpha) was used to evaluate the effects of TNF-alpha on VEGF secretion of ADSCs. ADSCs were cultured in the 6-well plates with $10^{5}$ cells per well in the culture medium (ADSCCult I completed medium, Regenmedlab, HCMC, VN) until 70\% confluency. The media were removed, and the fresh media supplemented to $0,10,20,40$, 60,80 , and $100 \mathrm{ng} / \mathrm{mL}$ of TNF-alpha (Thermo Fisher, MA) were used with $2 \mathrm{~mL}$ per well. The cells were cultured in an incubator with $5 \% \mathrm{CO}_{2}$, at $37^{\circ} \mathrm{C}$, and in $20 \%$ oxygen for $48 \mathrm{~h}$. The CM were collected, and the cell debris was removed by centrifugation at 3,000 $\mathrm{g}$ at $4^{\circ} \mathrm{C}$ for $15 \mathrm{~min}$. These $\mathrm{CM}$ were then used to measure VEGF concentration using an ELISA kit (Abcam).

A serial concentration of TNF-alpha $(0,10,20,40,60$, 80 , and $100 \mathrm{ng} / \mathrm{mL}$ of TNF-alpha) was used to evaluate the effects of TNF-alpha on the apoptosis of HUVECs. First, the HUVECs were seeded on the 6-well plates with $10^{5}$ cells per well in the culture medium (M200 medium supplemented with LVES, Thermo Fisher) until 70\% confluency. The media were removed, and the fresh media M200 (with LVES) supplemented to $0,10,20,40,60,80$, and $100 \mathrm{ng} / \mathrm{mL}$ of TNF-alpha (Thermo Fisher, MA) were used with $2 \mathrm{~mL}$ per well. The cells were cultured in an incubator with $5 \% \mathrm{CO}_{2}$, at $37^{\circ} \mathrm{C}$, and in $20 \%$ oxygen for $48 \mathrm{~h}$. The cells were then collected using the detachment reagent (Regenmedlab, HCMC, VN) and then evaluated for the percentage of apoptotic cells using the apoptosis kit, Annexin V/PI (BD Bioscience, MA). All assays were triplicated.

\section{Statistical analysis}

All assays were triplicated. Data were analyzed using the GraphPad Prism 8 software. The statistical analysis was performed using t-test. P-value $<0.05$ was considered significant. All data were presented as mean \pm standard deviation.

\section{RESULTS}

\section{Isolation and characterization of human ADSCs}

The isolated ADSCs exhibited full characteristics of MSCs suggested by ISCT regarding minimal criteria of MSCs. They displayed the fibroblast-like shape when adhered to the surface of plastic flasks. They also revealed that the marker profiles of MSCs were positive with CD44 (100\%), CD73 (100\%), CD90 (100\%), and CD105 (98.56\%) and negative with CD14 (0 \%), CD34 (0 \%), CD45 (0\%), and HLA-DR (0 $\%$ ) (Figure 1). These cells were successfully induced to osteoblasts that could be positive with Alizarin Red staining (Figure 2), chondroblasts that could be positive with Alcian blue staining (Figure 2), and adipocytes that could be positive with Oil Red O staining (Figure 2). 

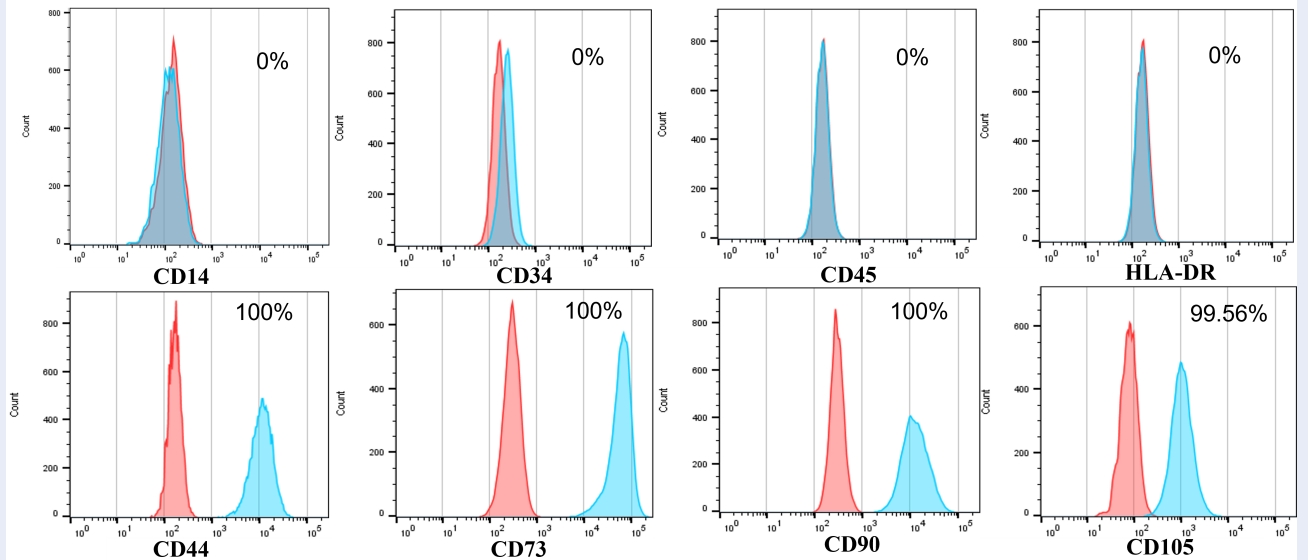

Figure 1: The isolated ADSCs from human adipose tissues displayed the particular marker profiles of MSCs. They highly expressed CD44, CD73, CD90, and CD105 and did not express CD14, CD34, CD45, and HLA-DR.
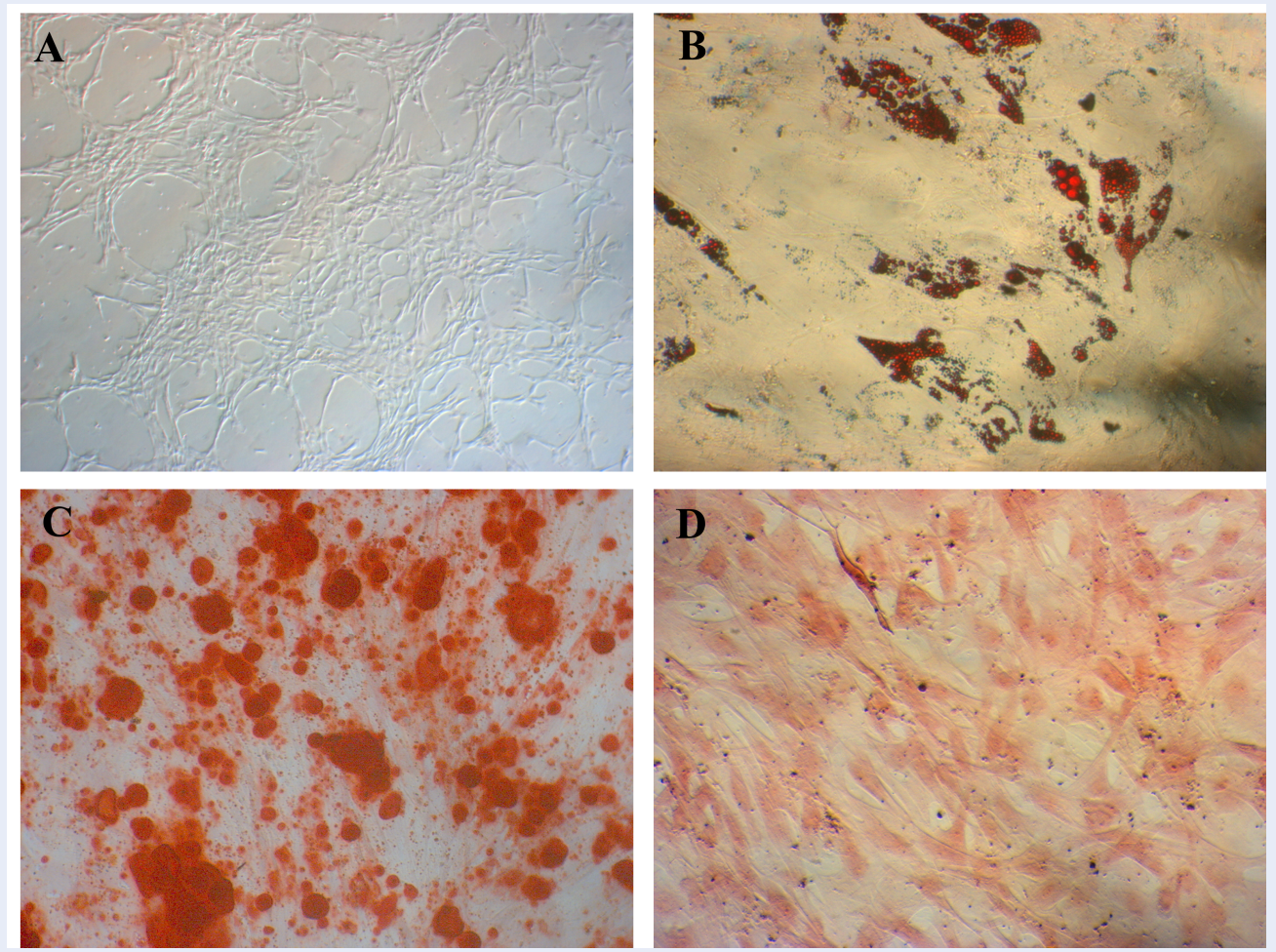

Figure 2: ADSC candidates could be successfully induced to adipocytes, osteoblasts, and chondrocytes in inducible media. After 21 days of induction, these cells could be positive to staining with Oil Red $\mathrm{O}$ (for adipogenesis induction), Alizarin Red (for osteogenesis induction), and Safranin O (for chondrogenesis induction). 


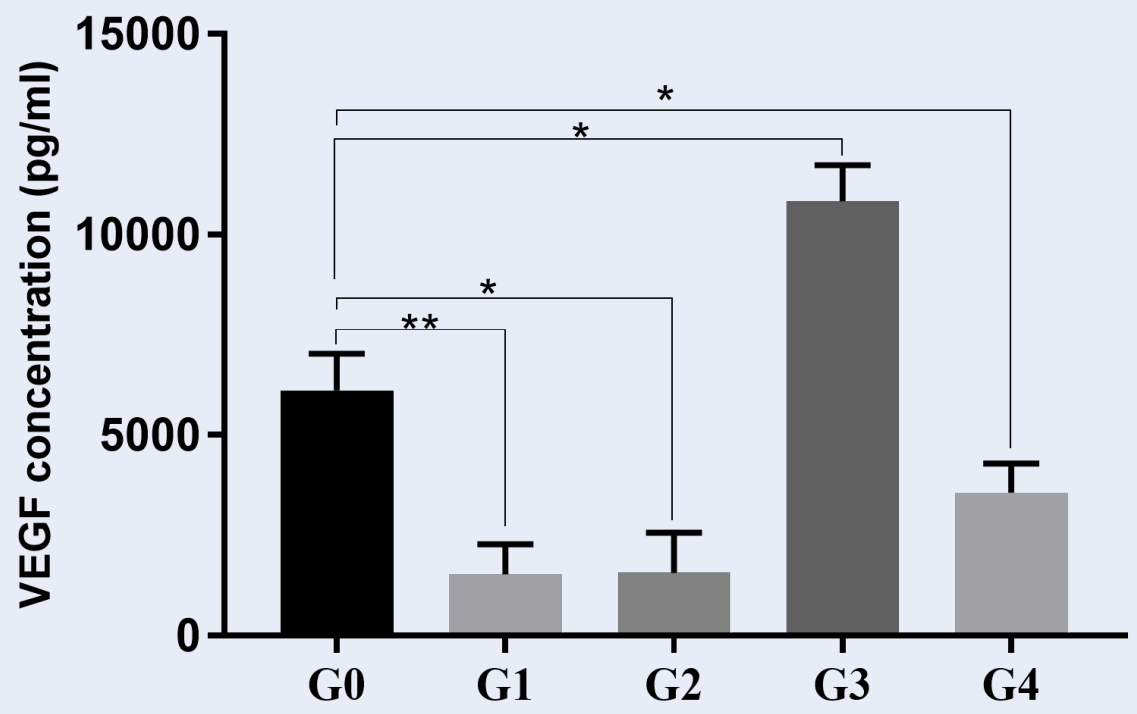

Figure 3: VEGF secretion in ADSC culture supernatants. In a normal culture condition (G0), ADSCs could secrete a high concentration of VEGF in the supernatant after $48 \mathbf{~ h}$ of culture. The VEGF secretion significantly increased in hypoxia (G3) and significantly reduced in TNF-alpha treatment (G1), starvation (G2), or in a combination of hypoxia and starvation (G4). ${ }^{*} p<0.05$ and ${ }^{* *} p<0.005$ ).

\section{VEGF secretion under different conditions}

The CM collected from different groups indicated different concentrations of VEGF. The highest concentration of VEGF was recorded in G3 in which the cells were treated in a hypoxia condition, and the lowest concentration of VEGF was recorded in G2 in which the cells were treated in TNF-alpha stress. The VEGF concentrations measured were $6,116 \pm 527.9$ $\mathrm{pg} / \mathrm{mL}, 1,536 \pm 432.1 \mathrm{pg} / \mathrm{mL}, 1,569 \pm 710 \mathrm{pg} / \mathrm{mL}$, $10,829 \pm 640 \mathrm{pg} / \mathrm{mL}$, and $3,574 \pm 505 \mathrm{pg} / \mathrm{mL}$ in the supernatants of G0, G1, G2, G3, and G4, respectively (Figure 3).

The results revealed that in a normal culture condition (G0, control), ADSCs could produce a high concentration of VEGF in the CM; however, this concentration could be increased in a hypoxia condition $(6,116$ $\pm 527.9 \mathrm{pg} / \mathrm{mL}$ vs. $10,829 \pm 640 \mathrm{pg} / \mathrm{mL}$, respectively, for normoxia vs. hypoxia condition; $\mathrm{p}<0.05)$. In the conditions of TNF-alpha treatment (G1), starvation (G2), or a combination of hypoxia and starvation (G4), the concentrations of VEGF in CM significantly reduced compared to the control (G0; $\mathrm{p}<$ $0.05)$. In conditions of TNF-alpha treatment (G1) and starvation (G2), the concentrations of VEGF were too low with a non-significant difference between these groups $(1,536 \pm 432.1 \mathrm{pg} / \mathrm{mL} v s .1,569 \pm 710 \mathrm{pg} / \mathrm{mL}$, respectively, for $\mathrm{G} 1$ vs. G2; $\mathrm{p}>0.05)$.

\section{$C M$ in stress conditions could stimulate an- giogenesis but not stressed by TNF-alpha}

The results showed that a CM from a normal culture condition (G0; without stress) could support the formation of vascular blood tubes from HUVECs in vitro. Under the microscope, the tubular structure was thin and unclear in this condition (Figure 4A). However, in G1, where ADSCs were treated with TNF-alpha, the HUVEC could not form the vessel structure in vitro (Figure 4 B). The CM from G2, G3, and G4 could support the blood vessel formation in vitro (Figure $4 \mathrm{C}, \mathrm{D}$, and $\mathrm{E}$ ).

The tubular structures from G0 and G2 were different from standard conditions (positive control) for vessel formation (using M200 medium supplemented with LVES) that could be detected under microscope observation. However, the tubular structures formed in CM from G3 and G4 were similar to that of a positive control (Figure 4). 
G0

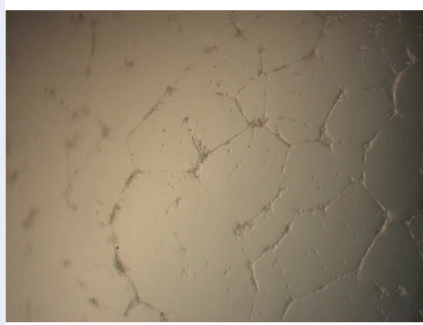

G3

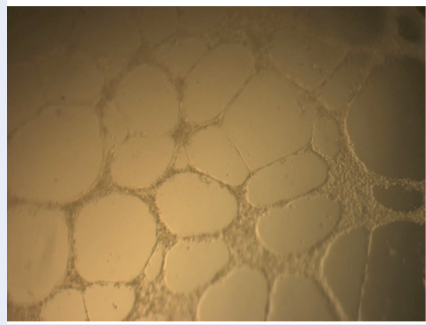

G1

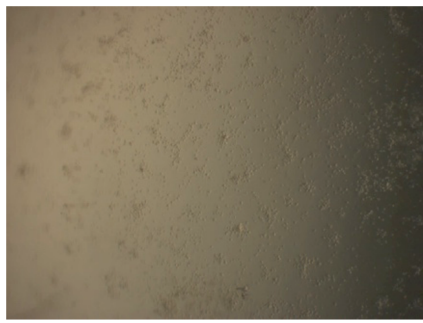

G4

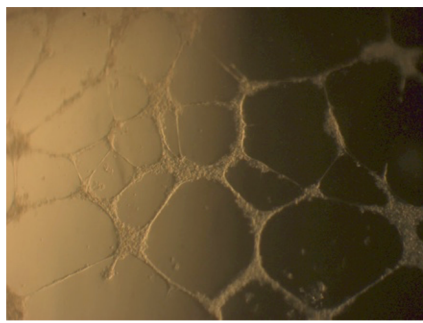

G2

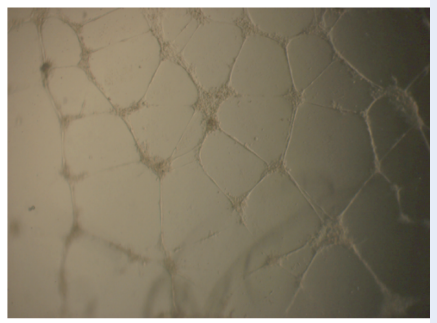

Positive control

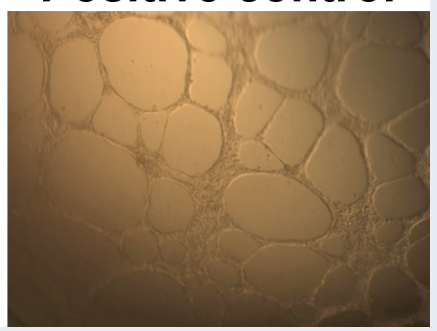

Figure 4: Blood vessel formation from HUVECs in vitro affected by some $\mathrm{CM}$. In the normal condition (without stress, G0), HUVECs could form blood vessels that were unclear and with thin structure (G0). In contrast, CM from TNF-alpha stress could not support blood vessel formation (G1), and CM from stress with hypoxia (G2), starvation (G3), and a combination of hypoxia and starvation (G4) could form blood vessels similar to that of the positive control.

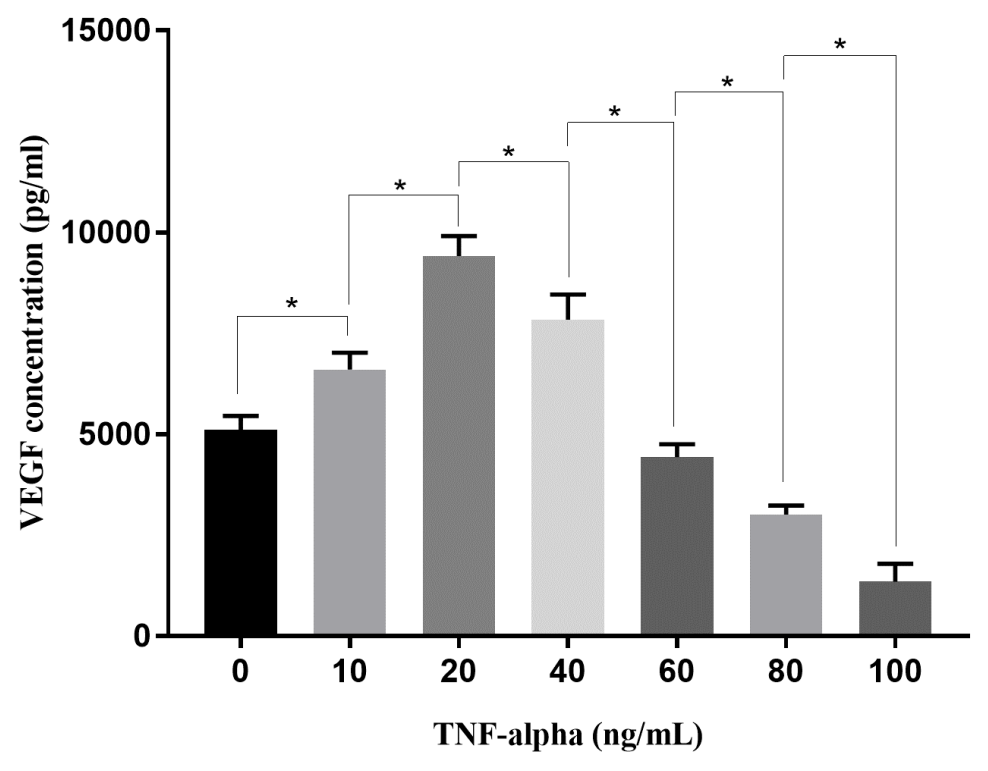

Figure 5: The VEGF secretion of ADSCs depends on the concentrations of TNF-alpha. At a low dose of TNFalpha, TNF-alpha stimulated VEGF secretion, while at the high dose (from $40 \mathrm{ng} / \mathrm{mL}$ ), TNF-alpha reduced VEGF secretion in ADSCs. 


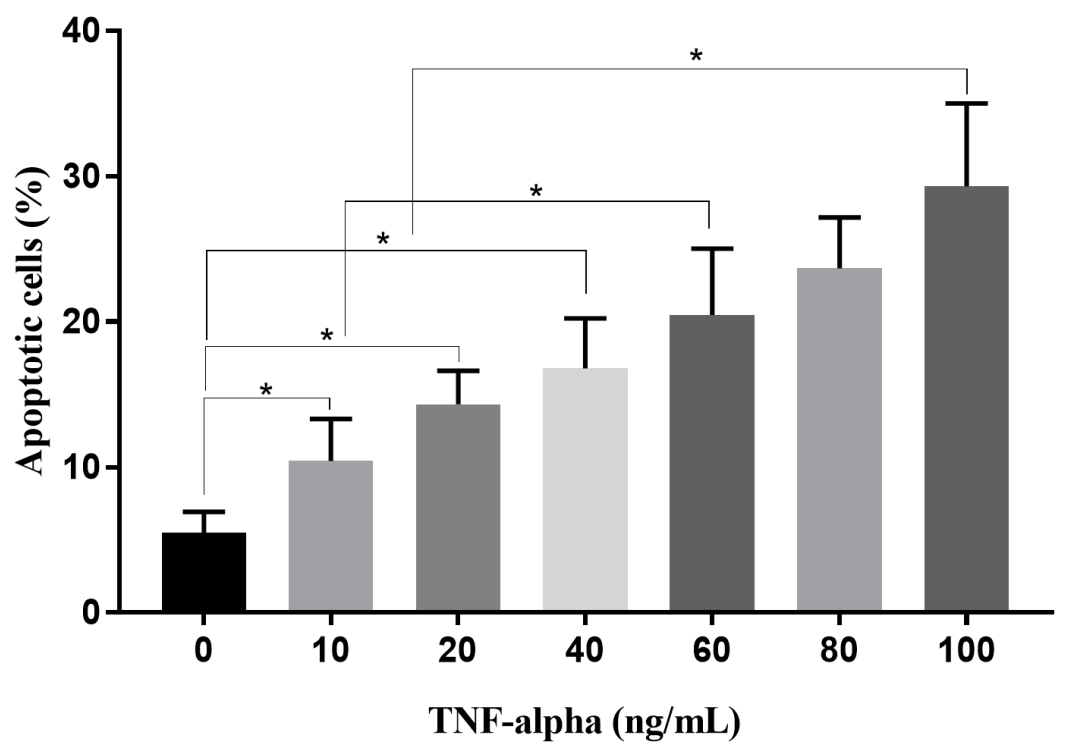

Figure 6: TNF-alpha could cause apoptosis in HUVECs. At a high concentration of TNF-alpha (100 ng/mL), about $30 \%$ of HUVECs underwent apoptosis. ${ }^{*} p<0.05$.

Dual effects of TNF-alpha on both ADSCs and HUVECs to reduce the angiogenesis potential

The effects of TNF-alpha on VEGF secretion of ADSCs were investigated in different doses $(10,20,40,60$, 80 , and $100 \mathrm{ng} / \mathrm{mL}$ ). The results revealed that VEGF secretion of ADSCs depends on the concentrations of TNF-alpha (Figure 5). The VEGF concentrations recorded in the $\mathrm{CM}$ at treatments of $10 \mathrm{ng} / \mathrm{mL}$ and $20 \mathrm{ng} / \mathrm{mL}$ of TNF-alpha were higher than that in the $\mathrm{CM}$ of control $(0 \mathrm{ng} / \mathrm{mL}$ of TNF-alpha; $6,600 \pm 420$ $\mathrm{pg} / \mathrm{mL}$ and $8,410 \pm 502 \mathrm{pg} / \mathrm{mL}$ in $10 \mathrm{ng} / \mathrm{mL}$ and 20 $\mathrm{ng} / \mathrm{mL}$, respectively, of TNF-alpha treatments compared to $5,105 \pm 346 \mathrm{pg} / \mathrm{mL}$ in control; $\mathrm{p}<0.05$ ). However, when TNF-alpha concentrations increased from $40 \mathrm{ng} / \mathrm{mL}$ to $100 \mathrm{ng} / \mathrm{mL}$, the VEGF concentrations in the CM gradually reduced. At concentrations of TNF-alpha $80 \mathrm{ng} / \mathrm{mL}$ and $100 \mathrm{ng} / \mathrm{mL}$, the VEGF concentrations were lower than that in control (3014 $\pm 221 \mathrm{pg} / \mathrm{mL}$ and $1343 \pm 453 \mathrm{pg} / \mathrm{mL}$, respectively, in groups of $80 \mathrm{ng} / \mathrm{mL}$ and $100 \mathrm{ng} / \mathrm{mL}$ of TNF-alpha treatments compared to $5,105 \pm 346 \mathrm{pg} / \mathrm{mL}$ in control; $\mathrm{p}<0.05)$.

To evaluate the effects of TNF-alpha in CM on HUVECs, HUVECs were treated with CM collected from culture media supplemented with various concentrations of TNF-alpha. The results revealed that percentages of apoptotic HUVECs gradually increased in response to increased TNF-alpha concentrations (Figure 6). At $0 \mathrm{ng} / \mathrm{mL}$ of TNF-alpha, there were $5.50 \pm 1.42 \%$ apoptotic HUVECs, while this ratio increased to $10.42 \pm 2.89 \mathrm{in} 10 \mathrm{ng} / \mathrm{mL}, 14.31 \pm 2.31 \%$ in $20 \mathrm{ng} / \mathrm{mL}, 16.77 \pm 3.45 \%$ in $40 \mathrm{ng} / \mathrm{mL}, 23.67 \pm 3.49$ $\%$ in $80 \mathrm{ng} / \mathrm{mL}$, and $29.32 \pm 5.68 \%$ in $100 \mathrm{ng} / \mathrm{mL}$ of TNF-alpha $(\mathrm{p}<0.05)$.

\section{DISCUSSION}

CM from MSCs is considered a promising cell-free agent for regenerative medicine. As more publications showed that the bio-effects of MSCs are mostly related to their secretomes, $\mathrm{CM}$ are of significant interest to researchers and pharmaceutical companies. $\mathrm{CM}$ are a combination of various factors such as soluble cytokines, EVs produced by MSCs, and culture media compositions. Under certain stress conditions, MSCs can change the gene expression and production of some cytokines and EVs that cause changes in their bioeffects on target cells. We proposed that when cultured in hypoxia, starvation, or a combination of hypoxia and starvation and TNF-alpha treatment, $\mathrm{AD}$ SCs can change the composition of their CM which in turn changes their angiogenic potential. Therefore, in this study, we treated ADSCs in four stress conditions: hypoxia, starvation, a combination of hypoxia and starvation, and TNF-alpha treatment and the assessment of CM on angiogenesis in vitro. 
In the first experiment, we confirmed that isolated ADSCs express the MSC phenotype as suggested by Dominici et al. $(2006)^{28}$. Indeed, these cells expressed that the marker profile of MSCs was positive with CD44, CD73, CD90, and CD105 and negative with hematopoietic cells CD14, CD34, CD45, and HLA-DR. Moreover, they could also be induced to mesenchymal cells, including osteoblasts, chondrocytes, and adipocytes in vitro.

In the subsequent experiment, the VEGF concentrations in CM collected under various stress conditions were measured. The results showed that ADSCs overexpressed VEGF production only in hypoxia, while in starvation, hypoxia and starvation, and TNF-alpha treatment, ADSC down-regulated VEGF production. Hypoxia can increase VEGF expression at mRNA and protein levels, which was also recorded in some published articles ${ }^{29-32}$. Liu et al. (2013) preconditioned ADSCs in 1\% oxygen and demonstrated that in this condition, ADSCs significantly increased the expression of angiogenic factors including VEGF and b$\mathrm{FGF}^{33}$. This observation was similar to MSCs from the bone marrow ${ }^{34}$. Lagonda et al. (2018) also showed that at a 3\% oxygen level, MSCs from umbilical cord tissue, bone marrow, and adipose tissue significantly increased VEGF synthesis and secretion compared to normoxia ${ }^{35}$. The mechanism under this observation is related to the activation of HIF-1 alpha caused by hypoxia ${ }^{36}$. The roles of HIF-1 alpha in angiogenesis are demonstrated in several studies ${ }^{37-40}$. Indeed, HIF-1 alpha is a transcription factor regulating the expression of angiogenesis, preventing apoptosis, and inducing migration of cells to ischemia. Hypoxia is known as a condition that induces the expression of HIF-1 alpha ${ }^{38,39}$. Besides the effects on VEGF production, hypoxia also causes universal effects on cell proliferation, cell metabolism, cell differentiation, cell apoptosis, and cell migration. In some studies, MSCs from the umbilical cord ${ }^{41}$, adipose tissue ${ }^{32}$, and urine stem cells ${ }^{42}$ could increase cell proliferation in hypoxic conditions $(1.5 \%-5 \% \text { oxygen })^{41}$, while in other studies, MSCs could reduce their proliferation in hypoxic condition ${ }^{43}$.

Starvation is also a common kind of stress that can change MSCs' characteristics. In this study, we found that starvation reduced VEGF production. This observation was also reported by Chua et al. $(2013)^{23}$ and Rezaie et al. (2018) ${ }^{44}$. The reason for this property has not been explained in the previous publications. This study also has not figured out why VEGF production reduced in starvation. We proposed that this characteristic could relate to cell proliferation that significantly reduces the stress of starvation conditions. The considerable decrease in VEGF production in starvation could cause a significant reduction of VEGF when ADSCs are treated with both the stresses of hypoxia and starvation.

The effects of TNF-alpha on the angiogenic potential of MSCs are also controversial. A few studies suggested that TNF-alpha could stimulate VEGF production in MSCs ${ }^{45-47}$, while others demonstrated that TNF-alpha is an inhibitor of VEGF production in $\mathrm{MSCs}^{48}$. In this study, the effects of TNF-alpha depended on its dose. At a low dose (below $40 \mathrm{ng} / \mathrm{mL}$ ), TNF-alpha could stimulate ADSCs to produce VEGF; however, at a higher dose, TNF-alpha inhibited VEGF production.

However, the reduction of VEGF in the CM did not directly affect the failure of CM from TNF-alphastressed ADSC culture in the blood vessel formation of HUVECs. Indeed, the results indicate that in hypoxia (G2) and hypoxia combined with starvation (G4), the levels of VEGF were similar to that of TNFalpha treatment (G1), but their CM also supported blood vessel formation of HUVECs in vitro. Based on this finding, we propose that the remaining TNFalpha in CM had a direct negative effect on the HUVECs and inhibited blood vessel formation. Under a microscope, we found that almost all HUVECs could enter an apoptotic phase. Therefore we propose that TNF-alpha could cause apoptosis in HUVECs in the next experiment.

To demonstrate that CM from TNF-alpha-stressed ADSC culture depends on reducing VEGF and that the percentage of apoptotic HUVECs directly depends on the concentration of TNF-alpha, CM derived from $100 \mathrm{ng} / \mathrm{mL}$ of TNF-alpha culture medium caused to $29.32 \pm 5.68 \%$ apoptotic HUVECs after 48 $\mathrm{h}$ of treatment. Hence, the effects of TNF-alpha in culture medium affect both ADSCs and HUVECs. Furthermore, although it can enhance VEGF production at low doses, TNF-alpha directly drives HUVECs to apoptosis; the blood vessel formation assay confirmed this analysis.

Blood vessels could be formed in vitro from HUVECs in CM from control (without stress), hypoxia, starvation, and starvation and hypoxia but not in the TNFalpha stress group. The VEGF concentration can affect the angiogenic potential of these CM but does not depend on their concentration. In the starvation stress or starvation combined with hypoxia conditions, the VEGF concentration was also low compared to that in TNF-alpha stress. However, the blood vessel matrix could be formed in vitro. This implies that extra TNF-alpha in the CM of TNF-alpha stress 
ADSC culture inhibited the blood vessel formation of HUVECs. Moreover, TNF-alpha also changed the EV synthesis and production. Ahn et al. (2018) suggested that MSCs can produce EVs to carry and transfer VEGF to injured cells in models of neonatal hyperoxic lung injuries ${ }^{49}$.

\section{CONCLUSIONS}

CM from preconditioned MSC cultures are considered new components of regenerative medicine. CM can be used as free-cell therapy; they open up new opportunities for tissue healing. In this study, we found that CM from various culture conditions can directly affect VEGF production of ADSCs which in turn can change the angiogenic potential of CM. In hypoxic culture conditions, ADSCs strongly produce and secrete VEGF in the CM, while in starvation culture conditions as well as TNF-alpha treatment, ADSCs significantly reduced VEGF production. However, it seems that not only did VEGF in CM affect blood vessel formation of HUVECs but also had other effects. The extra TNF-alpha in CM of TNFalpha treatment negatively affects the blood vessel formation by promoting apoptosis of HUVECs. Other mechanisms underlying this observation that can relate to the EVs and exosome synthesis and production of ADSCs treated with TNF-alpha have not been evaluated in this study.

\section{ABBREVIATIONS}

ADSC: Adipose derived stem cell

CM: Conditioned medium

HGF: Hepatic growth factor

HUVEC: Human umbilical vein endothelial cell

IGF: Insulin-like growth factor

IL: Interleukin

MCP: Monocyte chemotactic factor

MSC: Mesenchymal stem cell

SDF: Stromal cell-derived factor

TNF: Tissue necrosis factor

VCAM: Vascular cell adhesion protein

VEGF: Vascular endothelial growth factor

\section{ACKNOWLEDGMENTS}

Authors thank Van Hanh General Hospital, Ho Chi Minh City, Viet Nam approved to use the adipose tissues from donors for the study.

\section{AUTHOR'S CONTRIBUTIONS}

Phuc Van Pham contributed to the conceptualization and design of the study, the acquisition, analysis and interpretation of data. Ngoc Bich Vu, Binh Thanh Vu and Khanh Nha Nguyen were for drafting the article and revising the article critically for important intellectual content. All authors read and approved the final manuscript.

\section{FUNDING}

This work is supported by Vietnam National University Ho Chi Minh City, No.TX2019-18-02.

\section{AVAILABILITY OF DATA AND MATERIALS}

Data and materials used and/or analyzed during the current study are available from the corresponding author on reasonable request.

\section{ETHICS APPROVAL AND CONSENT TO PARTICIPATE}

Not applicable.

\section{CONSENT FOR PUBLICATION}

Not applicable.

\section{COMPETING INTERESTS}

The authors declare that they have no competing interests.

\section{REFERENCES}

1. Das M, Sundell IB, Koka PS. Adult mesenchymal stem cells and their potency in the cell-based therapy. J Stem Cells. 2013;8(1):1-16. PMID: 24459809.

2. Fazzina $R$, ludicone $P$, Fioravanti $D$, Bonanno $G$, Totta P, Zizzari IG. Potency testing of mesenchymal stromal cell growth expanded in human platelet lysate from different human tissues. Stem Cell Res Ther. 2016;7(1):122. PMID: 27557940. Available from: 10.1186/s13287-016-0383-3.

3. Nolta JA, Galipeau J, Phinney DG. Improving mesenchymal stem/stromal cell potency and survival: Proceedings from the International Society of Cell Therapy (ISCT) MSC preconference held in May 2018, Palais des Congres de Montreal, Organized by the ISCT MSC Scientific Committee. Cytotherapy. 2020;22(3):123-6. PMID: 32067856. Available from: 10.1016/j. jcyt.2020.01.004.

4. Sagaradze G, Grigorieva O, Nimiritsky P, Basalova N, Kalinina N, Akopyan Z. Conditioned medium from human mesenchymal stromal cells: towards the clinical translation. Int J Mol Sci. 2019;20(7):1656. PMID: 30987106. Available from: 10.3390/ ijms20071656.

5. Kay AG, Long G, Tyler G, Stefan A, Broadfoot SJ, Piccinini AM. Mesenchymal stem cell-conditioned medium reduces disease severity and immune responses in inflammatory arthritis. Sci Rep. 2017;7(1):18019. PMID: 29269885. Available from: 10. 1038/s41598-017-18144-w.

6. Chen YC, Chang YW, Tan KP, Shen YS, Wang YH, Chang CH. Can mesenchymal stem cells and their conditioned medium assist inflammatory chondrocytes recovery? PLoS One. 2018;13(11):e0205563. PMID: 30462647 . Available from: 10.1371/journal.pone.0205563.

7. Chouw A, Milanda T, Sartika CR, Kirana MN, Halim D, Faried A. Potency of Mesenchymal Stem Cell and Its Secretome in Treating COVID-19. Regen Eng Transl Med. 2021;Online ahead of print:1-12. PMID: 33723519. Available from: 10.1007/s40883021-00202-5. 
8. Ho CH, Lan CW, Liao CY, Hung SC, Li HY, Sung YJ. Mesenchymal stem cells and their conditioned medium can enhance the repair of uterine defects in a rat model. J Chin Med Assoc. 2018;81(3):268-76. PMID: 28882732. Available from: 10.1016/j.jcma.2017.03.013.

9. Abdelwahab S, Elsebay SA, Gaber MF, Abdel-Hafez SM. Comparative study between bone marrow mesenchymal stem cell and their conditioned medium in the treatment of rat model of Parkinsonism. J Cell Physiol. 2021;236(1):440-57. PMID: 32557610. Available from: 10.1002/jcp.29872.

10. Kojima K, Kawahata I, Izumi H, Yoshihara S, Oki K, Fukunaga K. Intranasal Administration of Conditioned Medium from Cultured Mesenchymal Stem Cells Improves Cognitive Impairment in Olfactory Bulbectomized Mice. Adv Alzheimer Dis. 2020;9(03):47-56. Available from: 10.4236/aad.2020.93004.

11. Hong L, Yan L, Xin Z, Hao J, Liu W, Wang S. Protective effects of human umbilical cord mesenchymal stem cell-derived conditioned medium on ovarian damage. J Mol Cell Biol. 2020;12(5):372-85. PMID: 31742349. Available from: 10.1093/ jmcb/mjz105.

12. Shen C, Lie P, Miao T, Yu M, Lu Q, Feng T. Conditioned medium from umbilical cord mesenchymal stem cells induces migration and angiogenesis. Mol Med Rep. 2015;12(1):20-30. PMID: 25739039. Available from: 10.3892/mmr.2015.3409.

13. Lu H, Wang F, Mei H, Wang S, Cheng L. Human adipose mesenchymal stem cells show more efficient angiogenesis promotion on endothelial colony-forming cells than umbilical cord and endometrium. Stem Cells International. 2018;2018:7537589. Available from: 10.1155/2018/7537589.

14. Ogisu K, Fujio M, Tsuchiya S, Tsuboi M, Qi C, Toyama N. Conditioned media from mesenchymal stromal cells and periodontal ligament fibroblasts under cyclic stretch stimulation promote bone healing in mouse calvarial defects. Cytotherapy. 2020;22(10):543-51. PMID: 32798177. Available from: 10.1016/j.jcyt.2020.05.008.

15. Almeria C, Weiss R, Roy M, Tripisciano C, Kasper C, Weber V. Hypoxia conditioned mesenchymal stem cell-derived extracellular vesicles induce increased vascular tube formation in vitro. Front Bioeng Biotechnol. 2019;7:292. PMID: 31709251. Available from: 10.3389/fbioe.2019.00292.

16. Zhu LP, Tian T, Wang JY, He JN, Chen T, Pan M. Hypoxia-elicited mesenchymal stem cell-derived exosomes facilitates cardiac repair through miR-125b-mediated prevention of cell death in myocardial infarction. Theranostics. 2018;8(22):6163-77. PMID: 30613290. Available from: 10.7150/thno.28021.

17. Shin J, Rhim J, Kwon Y, Choi SY, Shin S, Ha CW. Comparative analysis of differentially secreted proteins in serum-free and serum-containing media by using BONCAT and pulsed SILAC. Sci Rep. 2019;9(1):3096. PMID: 30816242. Available from: 10. 1038/s41598-019-39650-z.

18. Jin S, Yang C, Huang J, Liu L, Zhang Y, Li S. Conditioned medium derived from FGF-2-modified GMSCs enhances migration and angiogenesis of human umbilical vein endothelial cells. Stem Cell Res Ther. 2020;11(1):68. PMID: 32070425. Available from: 10.1186/s13287-020-1584-3.

19. Park BW, Jung SH, Das S, Lee SM, Park JH, Kim H. In vivo priming of human mesenchymal stem cells with hepatocyte growth factor-engineered mesenchymal stem cells promotes therapeutic potential for cardiac repair. Sci Adv. 2020;6(13). PMID: 32284967. Available from: 10.1126/sciadv.aay6994.

20. Chen L, Xu Y, Zhao J, Zhang Z, Yang R, Xie J. Conditioned medium from hypoxic bone marrow-derived mesenchymal stem cells enhances wound healing in mice. PLoS One. 2014;9(4):e96161. PMID: 24781370. Available from: 10.1371/ journal.pone.0096161.

21. Xia X, Chiu PW, Lam PK, Chin WC, Ng EK, Lau JY. Secretome from hypoxia-conditioned adipose-derived mesenchymal stem cells promotes the healing of gastric mucosal injury in a rodent model. Biochim Biophys Acta Mol Basis Dis. 2018;1864(1):178-88. PMID: 28993190. Available from: 10.1016/j.bbadis.2017.10.009.
22. Page $P$, DeJong J, Bandstr A, Boomsma RA. Effect of serum and oxygen concentration on gene expression and secretion of paracrine factors by mesenchymal stem cells. International journal of cell biology. 2014;2014:601063. Available from: 10 1155/2014/601063.

23. Chua KH, Raduan F, Safwani WKW, Manzor NF, PingguanMurphy B, Sathapan S. Effects of serum reduction and VEGF supplementation on angiogenic potential of human adipose stromal cells in vitro. Cell Prolif. 2013;46(3):300-11. PMID: 23672290. Available from: 10.1111/cpr.12029.

24. Haraszti RA, Miller R, Dubuke ML, Rockwell HE, Coles AH, Sapp E. Serum deprivation of mesenchymal stem cells improves exosome activity and alters lipid and protein composition. iScience. 2019;16:230-41. PMID: 31195240. Available from: 10.1016/j.isci.2019.05.029.

25. Truong NC, Bui KH, Pham PV. Characterization of senescence of human adipose-derived stem cells after long-term expansion. Adv Exp Med Biol. 2019;2019(1084):109-28. PMID: 3024278. Available from: 10.1007/5584_2018_235.

26. Pham PV, Nguyen ST, Phan NL, Do NM, Vo PH. AdiposeDerived Stem Cells Can Replace Fibroblasts as Cell Control for Anti-Tumor Screening Assay. OncoTargets Ther. 2020;13:6417-23. PMID: 32753883. Available from: 10.2147/ OTT.S259114.

27. Pham HL, Pham PV. High glucose induces early senescence in adipose-derived stem cells by accelerating p16 and mTOR. Biomed Res Ther. 2019;6(6):3213-21. Available from: 10. 15419/bmrat.v6i6.548.

28. Dominici M, Blanc KL, Mueller I, Slaper-Cortenbach I, Marini F, Krause D. Minimal criteria for defining multipotent mesenchymal stromal cells. The International Society for Cellular Therapy position statement. Cytotherapy. 2006;8(4):315-7. PMID: 16923606. Available from: 10.1080/14653240600855905.

29. Shi XF, Wang H, Xiao FJ, Yin Y, Xu QQ, Ge RL. MiRNA-486 regulates angiogenic activity and survival of mesenchymal stem cells under hypoxia through modulating Akt signal. Biochem Biophys Res Commun. 2016;470(3):670-7. PMID: 26801559. Available from: 10.1016/j.bbrc.2016.01.084.

30. Lee SH, Lee YJ, Song CH, Ahn YK, Han HJ. Role of FAK phosphorylation in hypoxia-induced hMSCS migration: involvement of VEGF as well as MAPKS and eNOS pathways. Am J Physiol Cell Physiol. 2010;298(4):847-56. PMID: 20089932. Available from: 10.1152/ajpcell.00418.2009.

31. Wagegg M, Gaber T, Lohanatha FL, Hahne M, Strehl C, Fangradt M. Hypoxia promotes osteogenesis but suppresses adipogenesis of human mesenchymal stromal cells in a hypoxia-inducible factor-1 dependent manner. PLoS One. 2012;7(9):e46483. PMID: 23029528. Available from: 10.1371/ journal.pone.0046483.

32. Pham PV, Vu NB, Phan NK. Hypoxia promotes adiposederived stem cell proliferation via VEGF. Biomed Res Ther. 2016;3(01):476-82. Available from: 10.7603/s40730-0160004-x.

33. Liu L, Gao J, Yuan Y, Chang Q, Liao Y, Lu F. Hypoxia preconditioned human adipose derived mesenchymal stem cells enhance angiogenic potential via secretion of increased VEGF and bFGF. Cell Biol Int. 2013;37(6):551-60. PMID: 23505143. Available from: 10.1002/cbin.10097.

34. Ishiuchi N, Nakashima A, Doi S, Yoshida K, Maeda S, Kanai R. Hypoxia-preconditioned mesenchymal stem cells prevent renal fibrosis and inflammation in ischemia-reperfusion rats. Stem Cell Res Ther. 2020;11(1):130. PMID: 32197638. Available from: 10.1186/s13287-020-01642-6.

35. Lagonda C, Tjahjadi FB, Fauza D, Kusnadi Y. Hypoxia increases vegf secretion in multiple sources of mesenchymal stem cell. Cytotherapy. 2018;20(5):44-5. Available from: 10.1016/j.jcyt. 2018.02.114.

36. Dai Y, Xu M, Wang Y, Pasha Z, Li T, Ashraf M. HIF-1alpha induced-VEGF overexpression in bone marrow stem cells protects cardiomyocytes against ischemia. J Mol Cell Cardiol. 2007;42(6):1036-44. PMID: 17498737. Available from: 10 1016/j.yjmcc.2007.04.001. 
37. Peterson KM, Aly A, Lerman A, Lerman LO, Rodriguez-Porcel M. Improved survival of mesenchymal stromal cell after hypoxia preconditioning: role of oxidative stress. Life Sci. 2011;88(12):65-73. PMID: 21062632. Available from: 10.1016/j.lfs.2010. 10.023 .

38. Wang JA, Chen TL, Jiang J, Shi H, Gui C, Luo RH. Hypoxic preconditioning attenuates hypoxia/reoxygenation-induced apoptosis in mesenchymal stem cells. Acta Pharmacol Sin. 2008;29(1):74-82. PMID: 18158868. Available from: 10.1111/j. 1745-7254.2008.00716.x.

39. Kim HW, Haider HK, Jiang S, Ashraf M. Ischemic preconditioning augments survival of stem cells via miR-210 expression by targeting caspase-8-associated protein 2. J Biol Chem. 2009;284(48):33161-8. PMID: 19721136. Available from: 10 1074/jbc.M109.020925.

40. Pasha Z, Wang Y, Sheikh R, Zhang D, Zhao T, Ashraf M. Preconditioning enhances cell survival and differentiation of stem cells during transplantation in infarcted myocardium. Cardiovasc Res. 2008;77(1):134-42. PMID: 18006467. Available from: $10.1093 / \mathrm{cvr} / \mathrm{cvm} 025$.

41. Lavrentieva A, Majore I, Kasper C, Hass R. Effects of hypoxic culture conditions on umbilical cord-derived human mesenchymal stem cells. Cell Commun Signal. 2010;8(1):18. PMID: 20637101. Available from: 10.1186/1478-811X-8-18.

42. Kwon SY, Chun SY, Ha YS, Kim DH, Kim J, Song PH. Hypoxia Enhances Cell Properties of Human Mesenchymal Stem Cells. Tissue Eng Regen Med. 2017;14(5):595-604. PMID: 30603513. Available from: 10.1007/s13770-017-0068-8.

43. Holzwarth C, Vaegler M, Gieseke F, Pfister SM, Handgretinger $\mathrm{R}$, Kerst $\mathrm{G}$. Low physiologic oxygen tensions reduce proliferation and differentiation of human multipotent mesenchymal stromal cells. BMC Cell Biol. 2010;11(1):11. PMID: 20109207. Available from: 10.1186/1471-2121-11-11.

44. Rezaie J, Mehranjani MS, Rahbarghazi R, Shariatzadeh MA. Angiogenic and Restorative Abilities of Human Mesenchymal
Stem Cells Were Reduced Following Treatment With Serum From Diabetes Mellitus Type 2 Patients. J Cell Biochem. 2018;119(1):524-35. PMID: 28608561. Available from: 10 $1002 / j \mathrm{cb} .26211$.

45. Crisostomo PR, Wang Y, Markel TA, Wang M, Lahm T, Meldrum DR. Human mesenchymal stem cells stimulated by TNF-alpha, LPS, or hypoxia produce growth factors by an NF kappa Bbut not JNK-dependent mechanism. Am J Physiol Cell Physiol. 2008;294(3):675-82. PMID: 18234850. Available from: 10.1152/ajpcell.00437.2007.

46. Yang KQ, Liu Y, Huang QH, Mo N, Zhang QY, Meng QG. Bone marrow-derived mesenchymal stem cells induced by inflammatory cytokines produce angiogenetic factors and promote prostate cancer growth. BMC Cancer. 2017;17(1):878. PMID: 29268703. Available from: 10.1186/s12885-017-3879-z.

47. Wang M, Crisostomo PR, Herring C, Meldrum KK, Meldrum DR. Human progenitor cells from bone marrow or adipose tissue produce VEGF, HGF, and IGF-I in response to TNF by a p38 MAPK-dependent mechanism. Am J Physiol Regul Integ Comp Physiol. 2006;291(4):880-4. PMID: 16728464. Available from: 10.1152/ajpregu.00280.2006.

48. Terasaki H, Kase S, Shirasawa M, Otsuka H, Hisatomi T, Sonoda S. TNF- $\alpha$ decreases VEGF secretion in highly polarized RPE cells but increases it in non-polarized RPE cells related to crosstalk between JNK and NF- $\kappa$ B pathways. PLoS One. 2013;8(7):e69994. PMID: 23922887. Available from: 10.1371/ journal.pone.0069994.

49. Ahn SY, Park WS, Kim YE, Sung DK, Sung SI, Ahn JY. Vascular endothelial growth factor mediates the therapeutic efficacy of mesenchymal stem cell-derived extracellular vesicles against neonatal hyperoxic lung injury. Exp Mol Med. 2018;50(4):112. PMID: 29650962. Available from: 10.1038/s12276-0180055-8. 